\title{
Epistemic authority of professors and researchers: differential perceptions by students from two cultural-educational systems
}

\author{
Jos Hornikx
}

Received: 30 January 2010 / Accepted: 22 June 2010 / Published online: 30 July 2010 (C) The Author(s) 2010. This article is published with open access at Springerlink.com

\begin{abstract}
Teachers and researchers are considered epistemic authorities that provide reliable information if that information is relevant to their discipline. Students differentiate between relevant and irrelevant disciplines when assessing teachers' expertise. In this paper, it is investigated whether students' cultural-educational background plays a role in this differentiation between relevant and irrelevant disciplines. In large power distance cultures such as France, students learn to respect and obey their teacher, whereas in smaller power distance cultures such as the Netherlands, the relationships between students and teachers are more informal. Therefore, French students may be less sensitive to the actual discipline when assessing a source's expertise. In an experiment, it was empirically tested whether French students perceived smaller differences than Dutch students between fictitious professors and researchers who put forward information that was or was not related to their own discipline. Results showed that the French participants indeed differentiated to a much lesser degree between professors and researchers with a relevant and an irrelevant discipline than did the Dutch participants. Further analyses indicated that students' obedience partially mediated this effect of nationality on the difference between relevant and irrelevant disciplines. This study underlines the role that cultural-educational background can play in the assessments of epistemic authorities.
\end{abstract}

Keywords Culture $\cdot$ Discipline $\cdot$ Epistemic authority $\cdot$ Obedience $\cdot$ Power distance

\footnotetext{
J. Hornikx $(\varangle)$

Centre for Language Studies, Department of Business Communication Studies, Radboud University

Nijmegen, Erasmusplein 1, P.O. Box 9103, 6500 HD Nijmegen, The Netherlands

e-mail: j.hornikx@ let.ru.nl
} 


\section{Introduction}

In the educational system, teachers play an important role in transmitting knowledge to pupils and students. From the perspective of lay epistemic theory (Kruglanski 1989), teachers can be considered epistemic authorities (see Raviv et al. 2003). In this theory, which describes the process of knowledge acquisition, an epistemic authority is considered a source which one relies upon to acquire knowledge. Any person can become an epistemic authority, as long as others trust that he or she can provide reliable information. Different characteristics can make a source an epistemic authority, such as the source's role (e.g., leader, teacher), education (e.g., Ph.D.) or demographics (e.g., age). Teachers and researchers are prototypical examples of epistemic authorities.

Epistemic authorities may provide knowledge in a specific area that regards their own discipline such as when a language teacher explains a specific grammatical construction. Epistemic authorities may also give information on domains that exceed their own discipline. In those cases, people may even believe that a source is knowledgeable in a wide range of topics: a generalized epistemic authority (Kruglanski et al. 2005, 2009). Empirical studies have demonstrated that students' age affects the extent to which they consider teachers generalized epistemic authorities (e.g., Raviv et al. 1990a,b). Younger pupils consider teachers generalized epistemic authorities, but when they grow older, they differentiate between teachers on the basis of their specific disciplines.

In this paper, it is investigated whether people's cultural-educational background also plays a part in this differentiation. The relationship between teachers and students is culture-dependent, as culture and education are strongly related to each other (e.g., Alexander 2000; Cairns et al. 2001). In large power distance cultures such as France, students learn to respect and obey their teacher, whereas in smaller power distance cultures such as the Netherlands, the relationships between students and teachers are more informal (Hofstede 1986). It has been suggested that students in France consider teachers omniscient (e.g., Blom 1995; Planel 1997), whereas students in the Netherlands develop a more critical attitude towards teachers and the information they provide (e.g., De Bony 2003; Hofstede 1986). Therefore, it was empirically tested whether French students perceive smaller differences than Dutch students between professors and researchers who put forward information that is or is not related to their own discipline.

\section{Epistemic authorities and their disciplines}

A number of studies have examined people's perceptions of teachers and other persons as epistemic authorities. Raviv et al. (1990a) investigated children's perceptions of mothers, fathers, teachers and friends as epistemic authorities. The children, who were aged from 4 to 9 years old, were asked who they thought knew best in different domains, such as social relations, rules, and personal feelings. The researchers were interested in changes of perceptions during childhood. The results pointed out that teachers and parents are both perceived as generalized epistemic authorities during this age span, and that friends become more important when it comes to social relations. 
In another study, Raviv et al. (1990b) investigated such perceptions for an older sample, namely children and adolescents from 9 to 18 years old. The findings showed that, when children become adolescents, the role of friends as epistemic authorities remains stable or even increases, whereas the role of teachers and parents as generalized epistemic authority diminishes. Teachers are still considered authorities in the domains of science and schools, but in other areas they are no longer epistemic authorities in the eyes of the adolescents. This means that adolescents, more than children, differentiate in the extent to which they rely on a given source depending on the domain. Teachers are no longer generalized epistemic authorities who are knowledgeable in a wide range of domains, but epistemic authorities on their own domain.

This sensitivity to the discipline of teachers has been corroborated in a few studies, such as Raviv et al. (1993, 2003). Participants in Raviv et al. (1993, study 2) were university students enrolled in psychology or statistics. They had to indicate to what extent they found one of the professors of their department an epistemic authority on his/her own domain and on various domains. Professors received higher scores as epistemic authorities on their own discipline than as epistemic authorities on various disciplines. In Raviv et al. (2003), the same kinds of questions were asked to high school students (12-16 years old). They considered their teachers in literature, mathematics, biology, and history more as epistemic authorities in their disciplinary domain than in the general domain.

In the research presented above, a teacher's epistemic authority was assessed on the basis of very broad knowledge domains, such as social relations, personal feelings, literature, and biology. In real life, students and other people rely on teachers or researchers when it comes to very specific knowledge, such as the effects of exercising and healthy food, or the factors that influence work productivity. Teachers and researchers can put forward claims on various topics, and the degree to which people accept these claims has been shown to depend on the sources' discipline or field of knowledge. A number of studies in social psychology and persuasion have demonstrated that people are sensitive to the relevance of the source's field of knowledge when he or she presents very specific claims (e.g., Luchok and McCroskey 1978; Maddux and Rogers 1980; Pornpitakpan and Francis 2001). In an experiment reported in Maddux and Rogers (1980), a claim about the desirability of 4 hours sleep a night was attributed to two different researchers: one was presented as an authority on sleep research and the other on music during the Baroque period. The results showed that people are sensitive to the degree of correspondence between the claim and the field of knowledge assigned to the source: the source specialized in sleep research was considered an expert on the topic (and was more persuasive), whereas a source with a specialization in music studies was not (and was less persuasive).

Combining the different research findings presented above, one can conclude that students (adolescents and older) only consider a teacher or researcher an epistemic authority when his or her discipline (domain of competence, field of expertise) is highly relevant to the topic in question. This topic may be rather broad (e.g., biology) or specific (e.g., the effects of climate change on cell production). Thus, students differentiate between sources on the basis of their actual discipline. Below, it will be argued that such differentiation is less pronounced for people raised in a cultural-educational system that underlines teachers' authority and students' obedience. 


\section{Epistemic authorities and educational systems}

Teachers in primary and secondary schools and in universities function as epistemic authorities that provide reliable information. The ways in which teachers transmit information may differ from culture to culture. Culture and education are strongly related to each other (e.g., Alexander 2000; Cairns et al. 2001). In education, information and values are transmitted from one generation to the other generation (Hofstede 1986; Lee 2001). As children start going to school at a young age, they learn what is important, and how to behave in their own culture early on. As Planel (1997, p. 351) puts it, "Children internalise the ground rules, values and expectations in the social world of their home and school". 'Teacher-student' is one of the role pairs through which culture is manifested (Hofstede 1986). The values that different cultures may emphasize are also learned in an educational environment. If a culture puts weight on respect, formal communication, and inequality, these values will also be prevalent in an educational context.

A number of studies have interpreted the relationship between teachers and students from the value dimension power distance (e.g., Joy and Kolb 2009; Neuliep 1997; Richardson and Smith 2007). Power distance is one of the dimensions on the basis of which cultural differences have successfully been characterized (Fiske et al. 1998). Hofstede (2001, p. 98) defines power distance as "the extent to which the less powerful members of institutions and organizations within a country expect and accept that power is distributed unequally". Power may vary from social status to prestige and from wealth to knowledge: those who possess more knowledge are more powerful than those who possess less knowledge. Power distance is a much broader concept than a specific educational system. Educational systems, however, may be considered a domain in which power distance is manifested. In education in large power distance cultures, the wisdom and authority of the teacher are highly valued. Students are not supposed to contradict or criticize teachers, and the system is teacher-centered (Hofstede 1986, 2001; Joy and Kolb 2009). In small power distance cultures, education is relatively student-centered, and students are encouraged to ask questions and to interact with teachers (e.g., Hofstede 1986, 2001; Joy and Kolb 2009). Israel, where the Raviv studies were conducted, is an example of a small power distance culture.

Some educational investigations have been conducted in small and large power distance cultures. Neuliep (1997), for instance, demonstrated that the immediacy between teachers and students in the large power distance culture Japan was much smaller than in the small power distance culture the United States. For France, another large power distance culture, it has been noted that authoritarianism plays an important part in education (Planel 1997). In French primary education, pupils receive information from the teacher and accept it: "Knowledge is received, not negotiated or reflexive" (Alexander 2000, p. 62). Pupils in France consider teachers omniscient (Planel 1997). Since the 15th century, French philosophers such as Rabelais have insisted on the need for omniscient and erudite instructors (Blom 1995). Today, French teachers at high school are still such instructors who are expected to spread a "culture générale" (Alexander 2000; Blom 1995). Blom (1995) compared the educational system in high schools in France and the Netherlands, which is a small power distance 
culture. She also remarks that Dutch education is student-centered and French education teacher-centered. The French researcher De Bony (2003) also observed that students in the Netherlands develop a more critical attitude towards teachers and the information they provide.

Differences in the relationship between teachers and students may also affect students' perceptions of teachers as epistemic authorities. Earlier studies (conducted in the small power distance culture Israel) report that students are sensitive to the discipline of the teacher (e.g., Raviv et al. 1993, 2003). French students do not put themselves in a position to critically assess their teachers (cf. Hofstede 1986; Planel 1997), and may be relatively less sensitive to the discipline of the teacher. There is some research evidence that students in the French educational system may indeed be rather insensitive to the teacher's domain of competence. Hornikx and Hoeken (2007, Study 2) examined the persuasiveness of different types of evidence in the Netherlands and France. One of the types of evidence was expert evidence, in which a university professor supported a given claim. Two kinds of experts were distinguished: professors who underlined a claim that was relevant to their own discipline, and professors who underlined a claim that was irrelevant to their discipline. Participants judged a number of claims that were supported by different types of evidence (among which the two kinds of expert evidence), and also assessed the expertise of these experts. Participants from France rated the expertise of professors as higher when their discipline was relevant than when it was irrelevant, but the effect was much smaller than what was found for participants from the Netherlands.

The experiment reported in Hornikx and Hoeken (2007, Study 2) was not specifically designed to study perceptions of epistemic authorities and their disciplines. Participants first rated the probability of a number of claims. After a handful of scales, they finally indicated the expertise of the experts they had read about earlier. In this design, participants' judgments of expertise may have been influenced by their earlier judgments of the claims. Also, they may not have been concentrated when assessing the expertise at the end of the questionnaire. Finally, the expertise ratings were based on four experts only, and were limited to judgments of professors, whereas people may also value information given by researchers. In order to address these limitations, the present study further examines judgments of epistemic authorities and their disciplines by students from France and the Netherlands. The study operationalizes epistemic authorities as professors and researchers that participants do not know personally. If students rate their own teachers (e.g., Raviv et al. 1993), the likeability of the teacher may play a role. Based on the literature on culture and education presented above, the following hypothesis is formulated:

H1: French students differentiate less between professors and researchers whose discipline is or is not relevant to the claim they underline than Dutch students

By investigating this hypothesis, the present study contributes to the understanding of how students assess professors and researchers as epistemic authorities, and of the extent to which students' cultural-educational background may affect these assessments. 


\section{Method}

An experiment was conducted in which Dutch and French university students were asked to judge the expertise of a number of different fictitious professors and researchers, each supporting a different claim that was or was not relevant to their own discipline.

\subsection{Material}

The material used claims that both Dutch and French participants perceived as moderately probable. For such claims, people can be expected to be more sensitive to the source's discipline. When claims are highly probable (e.g., "smoking increases the risk of lung cancer"), further support, such as expert opinions, does not matter. When claims are highly improbable (e.g., "smoking reduces the risk of lung cancer"), people disbelieve such claims regardless of the support provided (see Edwards and Smith 1996). Eight claims were borrowed from Hornikx and Hoeken (2007). A pretest had shown these eight claims to be moderately probable. On a 5-point scale, probability ratings of the claims ranged from 2.10 to 3.23 for the Dutch participants $(n=30)$ and 2.18-3.64 for the French participants $(n=28)$. The Dutch and French scores for each individual claim were not significantly different $(p \mathrm{~s}>$ $.05)$. The claims were related to different issues such as fear of driving cars, work productivity, and young criminals. For each claim, a relevant and an irrelevant discipline had been determined in a session with Dutch students (Hornikx and Hoeken 2007). Table 1 gives the eight claims in an English translation.

Table 1 Claims with relevant and irrelevant disciplines

\begin{tabular}{lll}
\hline Claim & Relevant discipline & Irrelevant discipline \\
\hline $\begin{array}{l}\text { Fear of flying decreases as a consequence of a } \\
\text { balloon flight. }\end{array}$ & Psychiatry & Business administration \\
$\begin{array}{c}\text { Keeping photos of family and friends on the } \\
\text { desk raises productivity at work. }\end{array}$ & Work psychology & Criminology \\
$\begin{array}{c}\text { Fear of driving cars can be taken away by } \\
\text { riding along with a truck driver for a day. }\end{array}$ & Behavioral therapy & Eye diseases \\
$\begin{array}{c}\text { Playing party games helps young criminals to } \\
\text { become more socialized. }\end{array}$ & Criminology & Music studies \\
$\begin{array}{c}\text { Waiters that repeat the orders of customers } \\
\text { verbatim receive a higher tip. }\end{array}$ & Social psychology & Psychiatry \\
$\begin{array}{c}\text { Too tight a tie leads to reduced sight. } \\
\begin{array}{c}\text { The consumption of basil in tomato pasta } \\
\text { sauce improves sporting performance. }\end{array}\end{array}$ & $\begin{array}{l}\text { Eye diseases } \\
\text { A regular change of workplace within a } \\
\text { company raises productivity at work. }\end{array}$ & Business administration \\
\hline
\end{tabular}

Disciplines were either relevant or irrelevant to the topics of the eight claims. In most cases, disciplines were used twice: once as a relevant and once as an irrelevant 
discipline. However, participants only received one discipline twice in the material they received, and the two claims with the same discipline did not succeed each other. In example (1), the discipline 'dietetics' is relevant to the claim about effects of basil; in example (2), the discipline 'didactics' is irrelevant to the same claim about the effects of basil.

(1) According to Professor Dr. Timmermans from the University of Amsterdam, a specialist in dietetics, the consumption of basil in tomato pasta sauce improves sporting performance.

(2) According to Professor Dr. Timmermans from the University of Amsterdam, a specialist in didactics, the consumption of basil in tomato pasta sauce improves sporting performance.

Half of the experts were researchers. These experts had the same manipulations as the professors, but the titles (Professor Dr.) were removed. Four types of experts were created on the basis of their discipline (relevant vs. irrelevant to the claim) and position (professor vs. researcher). Each of the eight experts that the participants encountered had a unique name and a unique affiliation to a Dutch or French university, excluding the participants' own universities. Participants received two instantiations of each of the four expert types. The material and instrumentation were originally developed in Dutch; the translation and back translation method (cf. Brislin 1980) ensured equivalent Dutch and French materials and instrumentation.

\subsection{Participants}

As studies have shown people to differentiate between sources' disciplines only from a certain age (e.g., Raviv et al. 1990a,b), university students were specifically selected as participants in this study. All Dutch and French students were from the faculty of Humanities; none of the claims was relevant to their degree programs. The Dutch participants $(n=106)$ studied at the Radboud University Nijmegen. The French participants $(n=112)$ studied at the University Marc-Bloch in Strasbourg. The Dutch participants were on average 19.69 years old $(S D=1.60)$, with ages ranging from 18 to 25 . The age of the French participants ranged from 18 to 26, with a mean of $19.67(S D=1.37)$. The percentage of female participants was higher in the French sample $(85.7 \%)$ than in the Dutch sample $(58.5 \%)\left(\chi^{2}(1)=20.23, p<\right.$ .001 ), but participants' gender did not affect the findings (as will be shown in the Sect. 5).

\subsection{Instrumentation}

In a booklet entitled 'Social issues', it was explained to students that they were to read a number of claims about social issues supported by experts. Below each claim, the participants indicated on a 5-point Likert scale the degree to which they found that each expert (professor or researcher) had enough expertise to make a judgment about a claim. 
Differences in expertise judgments of the Dutch and French were expected on the basis of the difference in the two educational systems, which place more (France) or less (the Netherlands) emphasis on obedience and respect. Therefore, participants' obedience, respect, and discipline were measured with two items from the Right-Wing Authoritarianism scale (RWA; Altemeyer 1988) on 5-point Likert scales: "Obedience and respect are the most important virtues children should learn" (RWA item 12), and "The real keys to the 'good life' are obedience, discipline, and sticking to the straight and narrow" (RWA item 26). Both items were combined in an obedience measure $(\alpha=.67)$.

An alternative explanation for a possible difference in the differentiation between experts' disciplines might be that French people simply are less inclined than Dutch people to critically process information. In order to measure participants' critical thinking, seven items of the Need for Cognition (NFC) scale were included, which measures the degree to which people spontaneously engage and thinking, and the degree to which they enjoy it (Cacioppo et al. 1984; $\alpha=.79$ ). A second alternative explanation might be that the French participants appreciate information given by experts more than the Dutch participants. Therefore, participants responded on a 5point Likert scale to four items of the Preference for Expert Information (PEI) scale from Hornikx and Hoeken (2007), which measures the degree to which people appreciate information given by experts $(\alpha=.81)$. The questionnaire ended with questions about participants' age, gender, nationality, and current education.

\subsection{Design}

Four versions of the material were constructed. In each version, participants received the eight claims in exactly the same order as presented in Table 1. The four versions differed in the distribution of the types of experts. In each version, a given claim was followed by one of the four different experts. A Latin square design ensured a balanced distribution of the expert types over the claims and the versions.

\subsection{Procedure}

Questionnaires were filled in at a university in Nijmegen and in Strasbourg. The students were not rewarded for their participation, which took about 8-10 min. After the questionnaires had been collected, the real research purpose was revealed, and participants were thanked for their cooperation.

\subsection{Statistical tests}

A 2 (nationality: Dutch vs. French) $\times 2$ (discipline: relevant vs. irrelevant) $\times 2$ (position: professor vs. researcher) analysis of variance with repeated measures was run, with nationality as between-subjects factor, and discipline and position as withinsubjects factors. In addition to these analyses by participants, analyses by stimuli were also conducted. 


\section{Results}

\subsection{Preliminary analyses}

Cross-cultural methodology recommends checking whether participants from different cultures use scales in the same way (Van de Vijver and Leung 1997). This is particularly appropriate in the present study since large and small power distance cultures have been found to use the endpoints of scales differently (Johnson et al. 2005). Bachman and O'Malley's (1984) index was used to test whether the Dutch and French participants differed in their use of the endpoints of the perceived expertise scales, but this was not the case $(t(216)=0.31, p=.76)$. Therefore, the raw data for perceived expertise were used for the analyses. For obedience, Need for Cognition (NFC), and Preference for Expert Information (PEI), French participants did use more endpoints than Dutch participants $(t(216)=3.19, p<.01)$. Therefore, scores on these scales were standardized. All analyses below involving obedience, NFC, and PEI use the standardized scores; for ease of interpretation, the descriptive statistics $(M, S D)$ are based on the raw data.

As the effect of discipline on perceived expertise was investigated for both researchers and professors, it was first checked whether position mattered. There was no interaction effect between discipline and position on perceived expertise for both the Dutch participants $\left(F_{1}(1,105)<1 ; F_{2}(1,7)<1\right)$ and the French participants $\left(F_{1}(1,111)<1 ; F_{2}(1,7)<1\right)$. This means that the relationship between discipline and perceived expertise was not affected by the position of the expert.

\subsection{Hypothesis}

H1 predicted a smaller effect of discipline on perceived expertise for the French participants than for the Dutch participants. This hypothesis was tested with a 2 (nationality) $\times 2$ (discipline) analysis of variance. There was a large interaction effect between nationality and discipline on expertise perception $\left(F_{1}(1,216)=105.34, p<\right.$ $\left..001, \eta^{2}=.33 ; F_{2}(1,14)=17.14, p<.01, \eta^{2}=.55\right)$. Evidence was found in support for $\mathrm{H} 1$ : the effect of the relevance of the discipline on expertise perception was indeed much smaller for the French than for the Dutch participants. For the Dutch participants, there was a very strong main effect of discipline on perceived expertise $\left(F_{1}(1,105)=357.70, p<.001, \eta^{2}=.77 ; F_{2}(1,7)=33.31, p<.01, \eta^{2}=.83\right)$ : experts with a relevant discipline $(M=3.81, S D=0.68)$ were considered as having much more expertise than experts with an irrelevant discipline $(M=2.20, S D=$ $0.57)$. For the French participants, the main effect of discipline on perceived expertise was considerably smaller $\left(F_{1}(1,111)=12.54, p<.01, \eta^{2}=.10 ; F_{2}(1,7)=\right.$ $\left.5.68, p<.05, \eta^{2}=.45\right)$ : experts with a relevant discipline $(M=2.97, S D=0.73)$ were considered as having slightly more expertise than experts with an irrelevant discipline $(M=2.65, S D=0.71)$. The Dutch and French perceptions of the expertise of the four types of experts are shown in Table 2 and visualized in Fig. 1.

H1 was expected on the basis of the difference between the role of obedience and respect in the educational systems in France and the Netherlands. The French 
Table 2 The perception of expertise of four types of experts

\begin{tabular}{lllll}
\hline & Dutch $(n=106)$ & \multicolumn{2}{l}{ French $(n=112)$} \\
\hline Type of expert & $M$ & SD & $M$ & SD \\
Professor & & & & 0.96 \\
$\quad$ Relevant discipline & $3.77^{\mathrm{a}}$ & 0.79 & $3.01^{\mathrm{a}}$ & 0.95 \\
$\quad$ Irrelevant discipline & $2.28^{\mathrm{b}}$ & 0.84 & $2.75^{\mathrm{b}, \mathrm{c}}$ & 0.94 \\
Researcher & & & & $2.93^{\mathrm{a}}, \mathrm{b}$ \\
$\quad$ Relevant discipline & $3.84^{\mathrm{a}}$ & 0.80 & $2.54^{\mathrm{c}}$ & 0.91 \\
Irrelevant discipline & $2.12^{\mathrm{b}}$ & 0.77 & \\
\hline
\end{tabular}

Different superscripts in the same column refer to significant differences, alpha level of .05
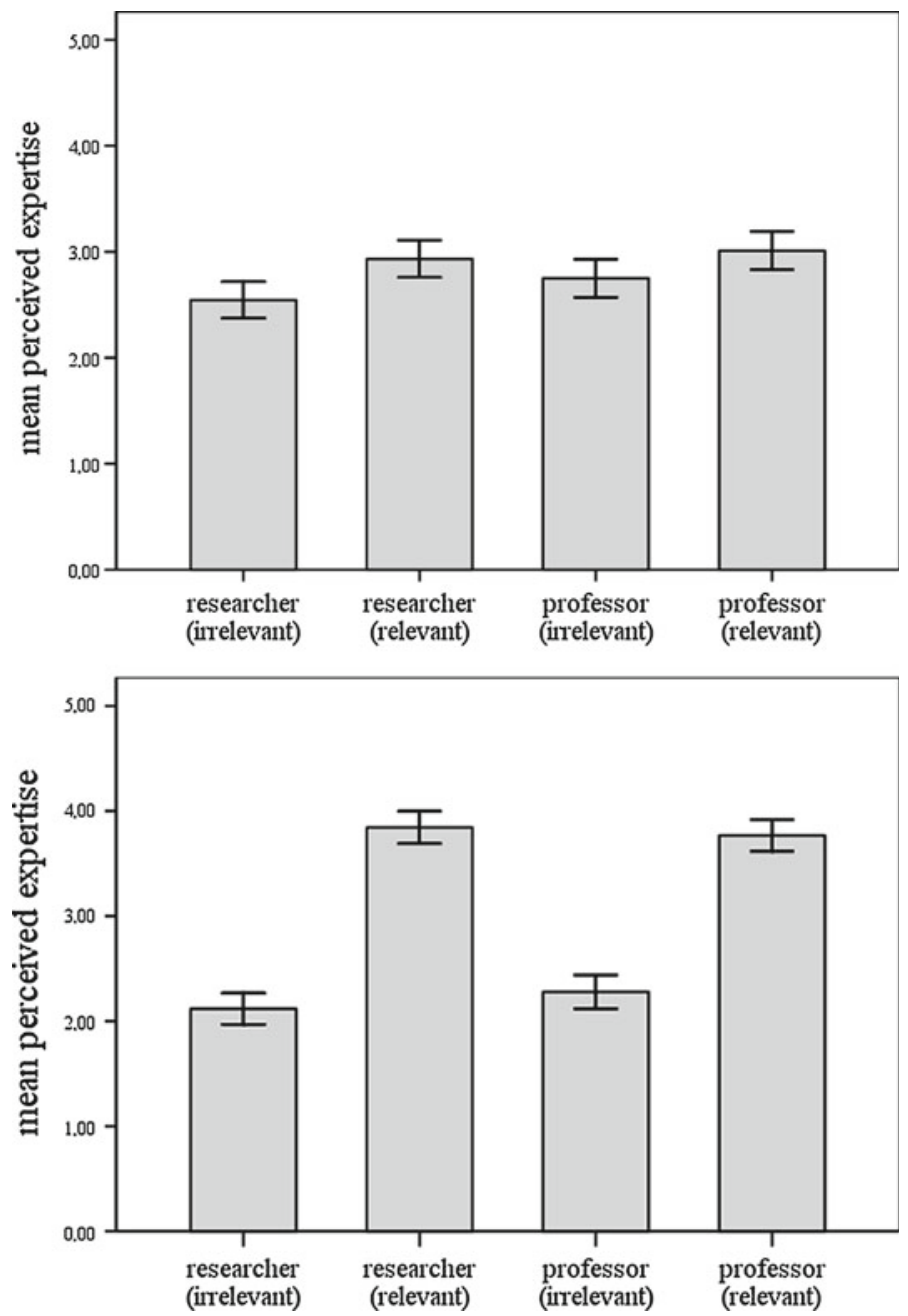

Fig. 1 Mean perceived expertise of four types of experts by French participants (top) and Dutch participants (bottom). Error bars show $95 \%$ confidence intervals 


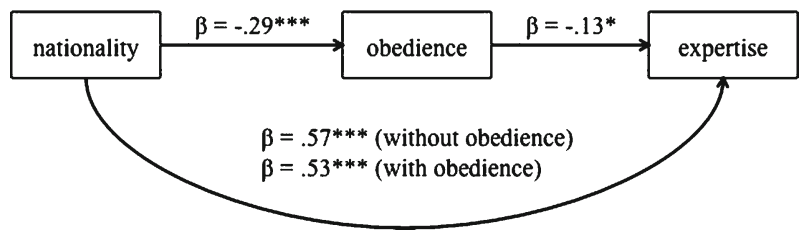

Fig. 2 Test of obedience as mediator between nationality (French or Dutch) and expertise assessment (difference between relevant and irrelevant discipline); $* p<.05$, *** $p<.001$

$(M=3.30, S D=0.99)$ indeed agreed more than the Dutch $(M=2.61, S D=0.92)$ that obedience, respect and discipline are important virtues $(t(216)=4.51, p<$ $.001)$. It was therefore investigated whether the obedience score was a mediator between the effect of nationality on expertise assessments, following the procedure described by Frazier et al. (2004). The dependent measure was the (newly computed) difference score between expertise of experts with a relevant discipline and expertise of experts with an irrelevant discipline. A larger difference score indicates a larger difference between relevant and irrelevant disciplines. Firstly, two independent regression analyses showed that nationality $(0=$ France, $1=$ the Netherlands $)$ was a significant predictor of the difference score in expertise $(\beta=.57, t=10.26, p<.001)$, and of obedience $(B=-.29, t=4.51, p<.001)$. Secondly, when controlling for nationality, obedience was also a significant predictor of expertise $(\beta=-.13, t=$ 2.28, $p<.05$ ): an increase in the difference between a relevant and an irrelevant discipline was predicted by a decrease in obedience. Thirdly, the Sobel (1982) test showed that the indirect effect of nationality on expertise through the mediator obedience was significant $(z=2.04, p<.05)$. It can be concluded that evidence was found that obedience partially mediates the effect of nationality on the difference between relevant and irrelevant disciplines. Figure 2 shows the relationships between the three variables.

An alternative explanation for the cross-cultural difference might be that the French participants were less inclined to critically process information than the Dutch participants. This explanation found no support, as the scores on Need for Cognition (NFC) for French $(M=3.28, S D=0.75)$ and Dutch $(M=3.13, S D=0.75)$ participants did not significantly differ $(t(216)=0.02, p=.99)$. A cultural difference was found, though, on the preference for expert information: contrary to earlier findings (Hornikx and Hoeken 2007), the Dutch $(M=2.66, S D=0.76)$ had a higher preference for expert information than the French $(M=2.40, S D=0.87 ; t(216)=2.69, p<.01)$. Preference for expert information was therefore not considered an alternative explanation for the cross-cultural difference in expertise judgments.

Finally, as the percentage of male participants was higher in the Dutch sample than in the French sample, the researchers checked whether gender affected the findings regarding H1. With the largely unequal sample sizes of men $(n=60)$ and women $(n=158)$, testing the difference between men and women with an analysis of variance would be inappropriate. Therefore, $\mathrm{H} 1$ was tested again with female participants only (France: $n=96$; the Netherlands: $n=62$ ). The results were similar to those in 
the main analysis. Again, there was a large interaction effect between nationality and discipline on the expertise perception $\left(F_{1}(1,156)=151.06, p<.001, \eta^{2}=.49\right)$. For the Dutch women, there was a very strong main effect of discipline on perceived expertise $\left(F_{1}(1,61)=188.81, p<.001, \eta^{2}=.76\right)$, while for the French women, there was a smaller main effect of discipline $\left(F_{1}(1,95)=8.11, p<.01, \eta^{2}=.08\right)$.

\section{Conclusion and discussion}

Studies have demonstrated that students consider teachers as epistemic authorities on their own discipline (e.g., Raviv et al. 1993, 2003). This means that teachers are believed to provide reliable information on the topics about which they are knowledgeable. The current study was conducted to test whether perceptions of professors and researchers as epistemic authorities are culture-dependent. In the French educational system, students learn to respect and obey their teachers, whereas students in the Dutch educational system adopt more critical attitudes towards teachers and information (e.g., De Bony 2003; Hofstede 1986; Planel 1997). It was therefore tested whether French students are less sensitive to the discipline of professors and researchers when they put forward claims than Dutch students.

A sample of university students from both countries indicated the degree to which they found that a number of professors or researchers possessed expertise to put forward a claim. As predicted, French students perceived a smaller difference in the expertise of experts with a relevant or an irrelevant field of expertise than did Dutch students, as in Hornikx and Hoeken (2007, Study 2). Not only is the size of this effect large, the direction of the effect is interesting too. Whereas the assessments of the Dutch students were clearly positive for the relevant disciplines and clearly negative for the irrelevant disciplines, the assessments of the French students were located around the midpoint of the scale (see Fig. 1). This means that the French students did not think the experts were all very knowledgeable, but that they were reluctant to sharply differentiate between the two kinds of professors or researchers.

Researchers tested whether the cross-cultural difference could be attributed to the students' obedience. A mediation analysis showed that obedience partially mediates the effect of nationality on the difference between relevant and irrelevant disciplines. On the one hand, this finding is in line with the literature on culture and education which suggests that obedience plays a significant role in large rather than in small power distance cultures (e.g., Hofstede 1986). On the other hand, the obedience measure that was used does not account for much of the variance in the difference scores between the expertise of sources with relevant and irrelevant disciplines. It is important to note that Need for Cognition (NFC) and Preference for Expert Information (PEI) do not appear to be alternative explanations for the results that were found. Therefore, it is plausible that the explanation of the cross-cultural difference could indeed be located in the obedience and respect of students, but future studies should use other measures to examine this role. One limitation of the current measure is that is was composed of only two items; more items are likely to better tap into the obedience construct. The two items were not geared at the participants' specific educational situation, but at the general importance of obedience and respect. It is possible that a measure of 
students' obedience to teachers or researchers they know personally is a better predictor of the difference scores between the expertise of sources with relevant and irrelevant disciplines.

In order to increase the generalizability of the results, this study used a number of different topics that experts supported. The experts (researchers and professors) were unknown to the students, excluding a possible effect of likeability. A study involving participants' own teachers would not have made this selection of different topics possible. A limitation of this design, however, is that the results cannot be directly transferred to the participants' own educational context. Do these results also apply to teachers and researchers they know? Also, do French students more easily accept the information that is put forward by teachers or researchers who are not knowledgeable? Such questions are also particularly relevant for educational practice. With the increasing number of students going abroad to study (temporarily) at a foreign university, teachers are faced with students from various cultural-educational backgrounds. This study underlines the role that culture may play in education in general, and in the perception of epistemic authorities in particular. It points to obedience as a partial explanation for the cross-cultural difference that was found, and thereby hopes to stimulate further studies to unravel how students' cultural-educational background affects perceptions of epistemic authorities.

Acknowledgments The author wishes to thank Remieg Aerts, Thomas Beaufils, Michèle Bitour, Jacqueline de Bony, Hans Hoeken, Claudia Huisman, Frank van Meurs, Margot van Mulken, and Evelyne Vos-Fruit for their suggestions regarding this research.

Open Access This article is distributed under the terms of the Creative Commons Attribution Noncommercial License which permits any noncommercial use, distribution, and reproduction in any medium, provided the original author(s) and source are credited.

\section{References}

Alexander, R. (2000). Culture and pedagogy: International comparisons in primary education. Malden, MA: Blackwell.

Altemeyer, B. (1988). Enemies of freedom: Understanding right-wing authoritarianism. San Francisco: Jossey-Bass.

Bachman, J. G., \& O’Malley, P. M. (1984). Yea-saying, nay-saying, and going to extreme: Black-white differences in response styles. Public Opinion Quarterly, 48(2), 491-509.

Blom, S. (1995). Intellectuele vorming in Nederland en Frankrijk: Een vergelijkend onderzoek naar deelname aan intellectuele vorming in het Franse en Nederlandse voortgezet onderwijs [Intellectual formation in the Netherlands and France: A comparative study of the participation in intellectual formation in Dutch and French secondary education]. Groningen: Wolters-Noordhoff.

Brislin, R. W. (1980). Translation and content analysis of oral and written material. In H. C. Triandis \& J. W. Berry (Eds.), Handbook of cross-cultural psychology: Methodology (pp. 389-444). Boston: Allyn \& Bacon.

Cacioppo, J. T., Petty, R. E., \& Kao, C. F. (1984). The efficient assessment of need for cognition. Journal of Personality Assessment, 48(3), 306-307.

Cairns, J., Lawton, D., \& Gardner, R. (Eds.). (2001). Values, culture and education. London: Kogan Page.

De Bony, J. (2003). Individual autonomy and socialization at the Dutch elementary school: The relationship between the individual and the group. In W. Jochems et al. (Eds.), Grenzeloos leren: 
Proceedings van de 30e onderwijs research dagen 2003 (pp. 110-112). Heerlen: Open Universiteit Nederland.

Edwards, K., \& Smith, E. E. (1996). A disconfirmation bias in the evaluation of arguments. Journal of Personality and Social Psychology, 71(1), 5-24.

Fiske, A. P., Kitayama, S., Markus, H. R., \& Nisbett, R. E. (1998). The cultural matrix of social psychology. In D. T. Gilbert, S. T. Fiske, \& G. Lindzey (Eds.), The handbook of social psychology (Vol. 2, 4th ed.) (pp. 915-981). Boston: McGraw-Hill.

Frazier, P. A., Tix, A. P., \& Baron, K. E. (2004). Testing moderator and mediator effects in counseling psychology research. Journal of Counseling Psychology, 51(1), 115-134.

Hofstede, G. (1986). Cultural differences in teaching and learning. International Journal of Intercultural Relations, 10(3), 301-320.

Hofstede, G. (2001). Culture's consequences: Comparing values, behaviors, institutions, and organizations across nations (2nd ed.). Thousand Oaks, CA: Sage.

Hornikx, J., \& Hoeken, H. (2007). Cultural differences in the persuasiveness of evidence types and evidence quality. Communication Monographs, 74(4), 443-463.

Johnson, T., Kulesa, P., Cho, Y. I., \& Shavitt, S. (2005). The relation between culture and response styles: Evidence from 19 countries. Journal of Cross-Cultural Psychology, 36(2), 264-277.

Joy, S., \& Kolb, D. A. (2009). Are there cultural differences in learning style? International Journal of Intercultural Relations, 33(1), 69-85.

Kruglanski, A. W. (1989). Lay epistemics and human knowledge: Cognitive and motivational bases. New York: Plenum.

Kruglanski, A. W., Raviv, A., Bar-Tal, D., Raviv, A., Sharvit, K., \& Ellis, S., et al. (2005). Says who? Epistemic authority effects in social judgment. Advances in Experimental Social Psychology, 37, 345-392.

Kruglanski, A. W., Dechesne, M., Orehek, E., \& Pierro, A. (2009). Three decades of lay epistemics: The way, how, and who of knowledge formation. European Review of Social Psychology, 20, 146-191.

Lee, W. O. (2001). Moral perspectives on values, culture and education. In J. Cairns, D. Lawton, \& R. Gardner (Eds.), Values, culture and education (pp. 27-45). London: Kogan Page.

Luchok, J. A., \& McCroskey, J. C. (1978). The effect of quality of evidence on attitude change and source credibility. The Southern Speech Communication Journal, 43(4), 371-383.

Maddux, J. E., \& Rogers, R. W. (1980). Effects of source expertness, physical attractiveness, and supporting arguments on persuasion: A case of brains over beauty. Journal of Personality and Social Psychology, 39(2), 235-244.

Neuliep, J. W. (1997). A cross-cultural comparison of teacher immediacy in American and Japanese college classrooms. Communication Research, 24(4), 431-451.

Planel, C. (1997). National cultural values and their role in learning: A comparative ethnographic study of state primary schooling in England and France. Comparative Education, 33(3), 349-373.

Pornpitakpan, C., \& Francis, J. N. P. (2001). The effect of cultural differences, source expertise, and argument strength on persuasion: An experiment with Canadians and Thais. Journal of International Consumer Marketing, 13(1), 77-101.

Raviv, A., Bar-Tal, D., Raviv, A., \& Abin, R. (1993). Measuring epistemic authority of politicians and professors. European Journal of Personality, 7(2), 119-138.

Raviv, A., Bar-Tal, D., Raviv, A., Biran, B., \& Sela, Z. (2003). Teachers' epistemic authority: Perceptions of students and teachers. Social Psychology of Education, 6(1), 17-42.

Raviv, A., Bar-Tal, D., Raviv, A., \& Houminer, D. (1990a). Development in children's perceptions of epistemic authorities. British Journal of Developmental Psychology, 8(2), 157-169.

Raviv, A., Bar-Tal, D., Raviv, A., \& Peleg, D. (1990b). Perception of epistemic authorities by children and adolescents. Journal of Youth and Adolescence, 19(5), 495-510.

Richardson, R. M., \& Smith, S. W. (2007). The influence of high/low context culture and power distance on choice of communication media: Students' media choice to communicate with professors in Japan and America. International Journal of Intercultural Relations, 31(4), 479-501.

Sobel, M. E. (1982). Asymptotic confidence intervals for indirect effects in structural equation models". In S. Leinhardt (Ed.), Sociological methodology (pp. 290-312). Washington, DC: American Sociological Association.

Van de Vijver, F. J. R., \& Leung, K. (1997). Methods and data analysis for cross-cultural research. Thousand Oaks, CA: Sage. 


\section{Author Biography}

Jos Hornikx (Ph.D., Radboud University Nijmegen) is an assistant professor in the department of Business Communication Studies at Radboud University Nijmegen, The Netherlands. His research interests include argumentation and evidence, and the impact of culture on persuasion. 